\title{
Application of Machine Vision to Collision Avoidance Control of the Overhead Crane
}

\author{
J.S. Yang \\ Department of Mechanical and Electro-Mechanical \\ Engineering \\ Tamkang University
}

\author{
W.F. Chien \\ Department of Mechanical and Electro-Mechanical \\ Engineering \\ Tamkang University
}

\begin{abstract}
The overhead crane is one of dangerous machines. It may cause personnel injury, or even property damages if any accidents happen in working area. Thus, to ensure safe operation, the load size, route and working environment should be taken into consideration. This study developed a safety alarm device for overhead crane to prevent impacting persons or objects, and used image processing technology to create a video surveillance system. It can track the target object automatically and maintain the preset distance between the warning limit and the hanging object as the hanging object ascends or descends. It can be applied on an overhead crane for early warning on collision and prevention of the hanging object from impacting the workers or other equipments. The distance between the obstacle and hanging object is estimated by using perspective projection, translation of axes and rotation skills, thus ensuring the safety effect.
\end{abstract}

Keywords-overhead crane; early warning of collision; image processing

\section{INTRODUCTION}

Under the rising trend of occupation safety, workers are demanding higher safety measures at the working environments. In recent years, the accidents involving overhead cranes have occurred frequently, causing injuries and damages in minor cases, or even bone fractures or deaths of workers and destruction of hanging objects in serious cases. Current studies on overhead cranes only use scaled down simulation to test automation, obstacle avoidance and improvement of the swing of hanging object resulted from sliding. The efficient method to solve early warning of collision of overhead crane is yet to be developed.

\section{LITERATURE REVIEW}

In recent years, machine automation has been an industrial trend, with advantages of low labor cost and long working hours. Hsu proposed the "overhead crane system with object-transporting and obstacle-avoiding" [1]. He used fuzzy controller to control the overhead crane to reach the destination. A camera was used to detect obstacles in the course of handling, so that the overhead crane could achieve obstacle avoidance and automatic handling functions. Jen proposed the "sliding-mode control of overhead crane systems

\author{
M.L. Huang \\ Department of Mechanical and Electro-Mechanical \\ Engineering \\ Tamkang University \\ M.H. Tsai \\ Department of Mechanical and Electro-Mechanical \\ Engineering \\ Tamkang University
}

using visual feedback" [2]. When the overhead crane is in operation, its sliding makes the hanging object swing. If the swing is violent, there may be a risk of impacting persons. That study used sliding mode controller and visual feedback to eliminate the swing caused by the sliding of overhead crane, thus reducing the risks of impacting persons. Some researchers used fuzzy control to improve the swing of hanging object caused by the sliding of overhead crane [3], and applied nonlinear coupling control law or fuzzy control to the overhead crane [4-5]. The above studies used the reduced model of overhead crane for test, but did not apply the model in actual operation. Moreover, as the current overhead crane is not automated, thus it cannot avoid obstacles automatically or reduce the swing of hanging object. Tsai proposed the "anti-collision control for an overhead crane" [6], which discussed the early warning of collision of actual overhead crane for the first time. That study set a warning limit on the video monitor screen.

\section{SYSTEM FRAMEWORK}

\section{A. Video Surveillance}

This study used a small chopping block to integrate camera, industrial battery and PoE power supply into a video monitoring module. Four strong magnets were fixed by screws to the back side of chopping block. The video monitoring module was installed on the overhead crane, adsorbed by strong magnets to the hoist of overhead crane (Figure 1).

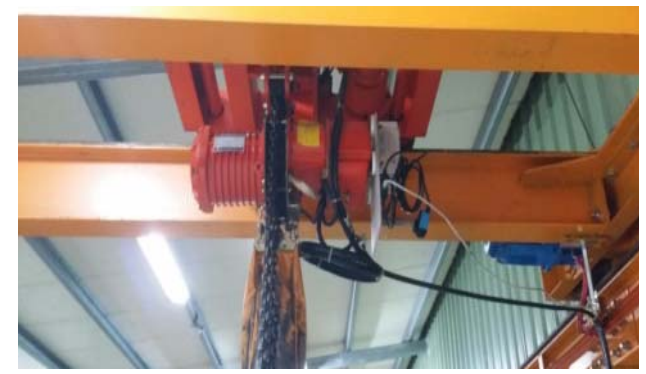

FIGURE I. SIDE VIEW OF INSTALLATION LOCATION OF VIDEO MONITORING MODULE 


\section{B. Warning System}

Figure 2 is the schematic diagram of the video monitoring device. The red straight line is the system set warning limit. Before hanging, the preset distance between warning limit and hanging object is set manually. When the video monitor detects a moving object or an obstacle in the warning limit, it raises the alarm immediately, the man-machine interface displays the warning message and the buzzer sounds, notifying the site operator immediately for real-time safety monitoring.

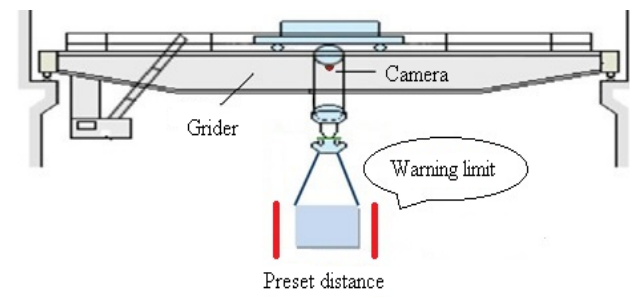

FIGURE II. SCHEMATIC DIAGRAM OF VIDEO MONITORING DEVICE IN AN OVERHEAD CRANE

\section{Early Warning Process}

The early warning process is shown in Figure 3. The computer performs remote monitoring, when the crane is started up, the camera monitors any moving object approaching the hanging object instantly. If a person or an obstacle enters the warning limit, an alarm is raised to notify the operators and onsite labors, so that the workers can make an appropriate decision instantly to avoid unnecessary impact injuries.

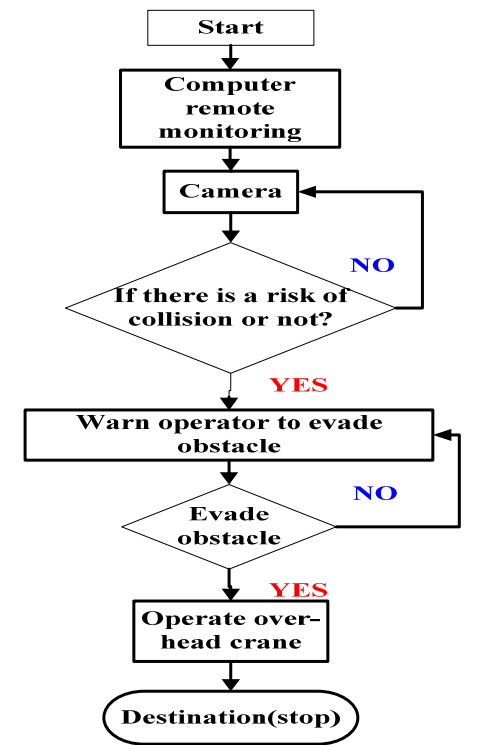

FIGURE III. .FLOW CHART OF EXPERIMENT

\section{SYSTEM FRAMEWORK}

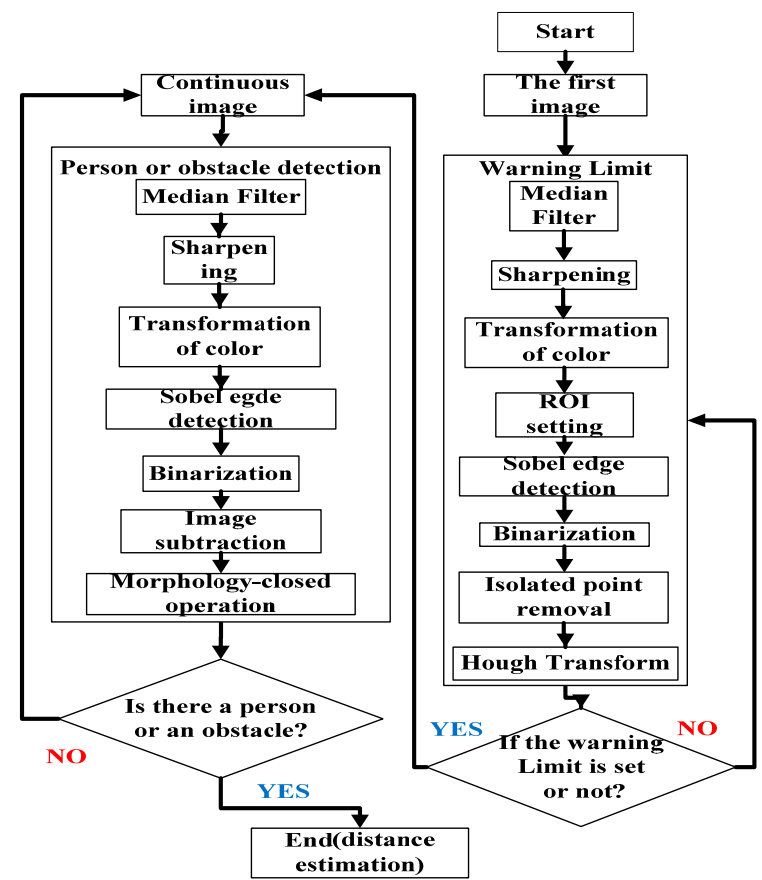

FIGURE IV. FLOW CHART OF COLLISION AVOIDANCE CONTROL ALGORITHM

Figure 4 is the flow chart of collision avoidance control algorithm. When the system is started, the first image is captured to set the warning limit. If the warning limit setting fails, the warning limit setting is executed again till it succeeds. When the warning limit is set successfully, the person or obstacle detection is executed. When a person or an obstacle is detected, the distance between the person or obstacle and the hanging object is estimated immediately.

\section{SYSTEM FRAMEWORK}

\section{A. Environmental Limits and Hypotheses}

The early warning collision-avoidance system for the overhead crane designed in this study is based on the actual hanging of overhead crane. The experimental area was $4 \mathrm{~m}(\mathrm{~L}) * 3 \mathrm{~m}(\mathrm{~W}) * 3.5 \mathrm{~m}(\mathrm{H})$, and the pallet is rectangular and the size of hanging object does not exceed the pallet in the experimental process.

\section{B. Experimental Results}

This experiment simulated and tested whether the system can detect the moving person before the overhead crane moves the hanging object, and whether the system can sound the alarm immediately for collision avoidance when a person enters the warning limit. Figure 5 is the schematic diagram of this experiment. The hanging object stayed in situ, and the person began to move towards the hanging object from horizontal distance of $3.5 \mathrm{~m}$ to the hanging object. The preset warning limit was $55 \mathrm{~cm}$ away from the hanging object. The experimental area was only $4 \mathrm{~m}$ long. If excluding the area of the pallet, the available length was about $3.5 \mathrm{~m}$. Therefore, the distance between the person and the hanging object was set as $3.5 \mathrm{~m}$. The overhead crane was $3.5 \mathrm{~m}$ high, and the camera 
mounting height was limited, so that the visual range of camera was narrow. If the warning limit exceeded $60 \mathrm{~cm}$, it exceeded the monitoring screen, so the distance between the warning limit and the hanging object was set as $55 \mathrm{~cm}$.

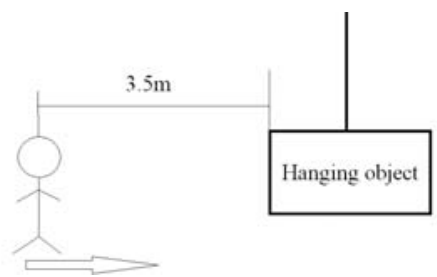

FIGURE V. FLOW CHART OF COLLISION AVOIDANCE CONTROL ALGORITHM

In Figure 6 (a), the person has not begun to move. When the person begins to move, the hanging object keeps still (Figure 6 (b)). When the person enters the monitor screen, the person has not entered the warning limit, the system has not sounded the alarm (Figure 6 (c)). When the person enters the warning limit, the man-machine interface pops up a warning message immediately, and sounds the alarm (Figure 6 (d)).

According to experimental verification, when the overhead crane is to move the hanging object, the system can detect the moving person, and it sounds the alarm once the person enters the warning limit, so as to avoid the operator moving the overhead crane while overlooking the person passing by for collision avoidance.

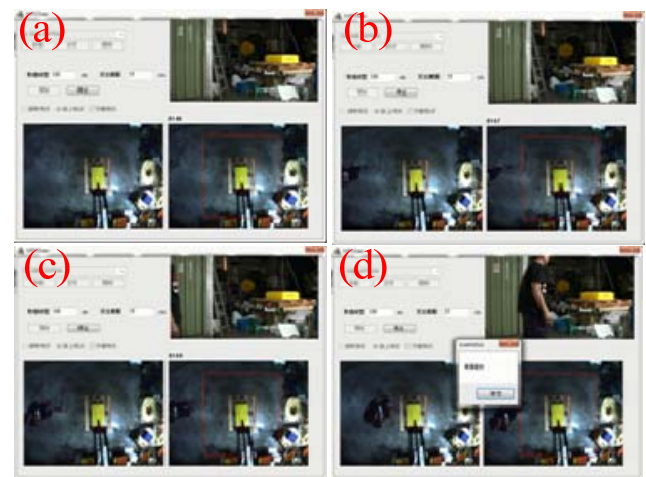

FIGURE VI. . EXPLODED DIAGRAM OF CONSECUTIVE FREEZE FRAMES OF PERSON MOVING TOWARDS HANGING OBJECT

This experiment validated that the warning limit would not change as the hanging object rises or falls, but maintain the preset range. Figure 7 is the schematic diagram of this experiment. The hanging object descended vertically from 1.7 $\mathrm{m}$ above ground, the person began to move towards the hanging object at horizontal distance of $3.5 \mathrm{~m}$ from the hanging object. The preset warning limit was $55 \mathrm{~cm}$ away from the hanging object.

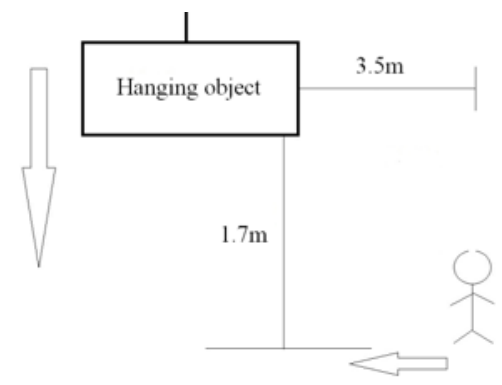

FIGURE VII. FLOW CHART OF COLLISION AVOIDANCE CONTROL ALGORITHM

The hanging object and the person have not begun to move (Figure 8 (a)). When the hanging object begins to fall, the person begins to move towards the hanging object (Figure 8 (b)). When the person enters the monitor screen, not yet in the warning limit, so the system has not sounded the alarm (Figure 8 (c)). When the person enters the warning limit, the man-machine interface pops up a warning message immediately, and sounds the alarm (Figure 8 (d)).

According to experimental verification, when the hanging object falls, the preset warning limit does not vary with the image feature size of hanging object, but keeps at $55 \mathrm{~cm}$ away from the hanging object.

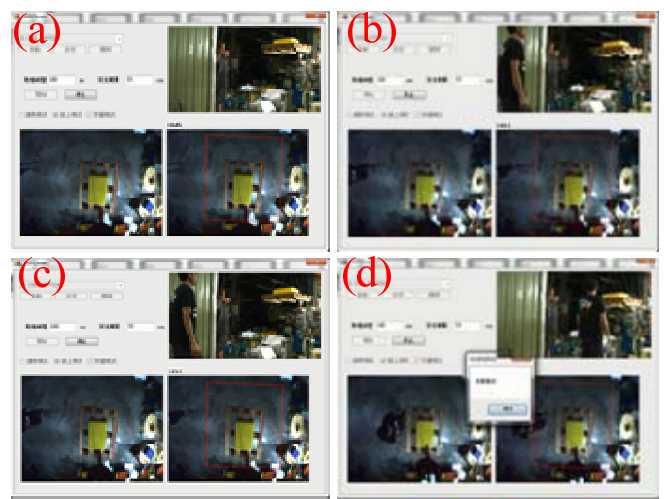

FIGURE VIII. FLOW CHART OF COLLISION AVOIDANCE CONTROL ALGORITHM

\section{EXPERIMENTAL RESUlts AND VALIDATION}

The method proposed in this paper has the following advantages: 1. One single image sensor can implement the collision avoidance control of overhead crane. Using one single image sensor can reduce the system cost and the program operation capacity, but the visual range of single lens is smaller than twin lens. 2 . The safe range is set according to the size of hanging object. 3 . The preset safe range does not change as the hanging object rises or falls, it maintains the preset range all the while.

In the experimental process, as limited to the visual range of lens and the height of overhead crane, the warning limit cannot be too large in this paper. If it is too large, it exceeds the size of image, the size of hanging object shall be restricted, otherwise, the warning limit cannot be set accurately. Therefore, future study can use appropriate overhead crane (e.g. high enough) or wider angle lens, so that the system can 
set a larger warning limit.

\section{REFERENCES}

[1] Hsu S. S., "The overhead crane system with object-transporting and obstacle-avoiding”, master's thesis, Department of Electrical Engineering, National Central University, June 2008.

[2] Jen C. L., "Sliding-Mode Control of Overhead Crane Systems Using Visual Feedback”, master's thesis, Department of Electrical Engineering, National Central University, 2006.

[3] Liu D. T., Yi J. Q., Zhao D. B. and Wang W., “Adaptive Sliding Mode Fuzzy Control for a Two-Dimensional Overhead Crane”, Mechatronics, vol.15, no.5, pp. 505-522,2005.

[4] Omar F., Karray F., Basir O. and Yu L., "Autonomous Overhead Crane System Usinga Fuzzy Logic Controller,” J. Vib. Control, vol. 10, pp. 1255-1270, 2004.

[5] Fang Y., Dixon W. E., Dawson D. M. and Zergeroglu E., "Nonlinear Coupling Control Laws for an Underactuated Overhead Crane System,” Mechatronics, vol.8, no. 3,pp. 418-423,2003.

[6] Tsai C. E., “Anti-Collision Control for an Overhead Crane”, master's thesis, Department of Mechanical and Electro-Mechanical Engineering, Tamkang University, June 2013. 